\title{
Methodology for Praxis-Oriented Development of a Building Refurbishment Concept Including Consideration of Potentially Existing Moisture Related Problems and Facade Restoration Measures
}

\author{
Heike Sonntag ${ }^{1, *}$, Prof.-Dr.-Ing. John Grunewald ${ }^{1}$ \\ ${ }^{1} \mathrm{TU}$ Dresden, Institute of Building Climatology, Germany
}

\begin{abstract}
When renovating historic buildings with facades worth preserving, the use of internal insulation is often the only way of thermal renovation of existing exterior walls. On the basis of the analysis of the building stock, suitable insulation concepts have to be developed. Demanding renovation planning, taking into account the requirements of the preservation of historical monuments, includes the determination of potential moisture-related causes of damage and the elaboration of measures for elimination and future damage prevention. In this paper, a renovation guide is presented that translates the scientific results of building physics research into renovation practice. As part of the knowledge transfer, the authors have been involved in renovation projects for years, using the methods and software tools they developed themselves. The individual steps of the refurbishment guide are explained using examples from refurbishment practice, starting with an on-site inspection, carrying out in-situ tests and measurements and determining the material properties in the laboratory. On this basis, necessary immediate measures for building protection can be formulated, and together with the owner / architect, various options regarding the intended use of the building and the actual condition determined in the investigation phase are developed. The development of the planning guide also allows conclusions to be drawn about the applicability of the simulation tools developed in the scientific environment and promotes their further development towards fully-fledged, economically usable planning tools.
\end{abstract}

\section{Phases of the refurbishment planning}

The planning of energy-related renovation measures on historic buildings, especially where internal insulation is planned, is carried out in three phases. It begins with a comprehensive assessment of the building and its condition. On this basis, a refurbishment concept can be developed. Only then, in the third step, is the selection and dimensioning of the constructive connection details and their optimization carried out.

The individual processing phases (Fig. 1) are presented in the following. This procedure has been used by the authors for the restoration planning for several years. Some examples of successfully refurbished projects are: historic storage buildings in Potsdam (Speicherstadt Potsdam, 2007-2012), historic buildings in the listed, former hospital ensemble „UrbanKrankenhaus“ in Berlin-Kreuzberg (2009 - 2012) [1], the quay storage building in Elbphilharmony Hamburg (2009 - 2014), a listed castle "Schloss Güterfelde“ (2011-2013), the former US-Army headquarter in Berlin (2011-2017), a former casern building "Rote Kaserne" in Potsdam (2014-2017) and the Franciscan monastery in
Zeitz (2018-2019). The guideline presented here is based on experience collected in these projects.

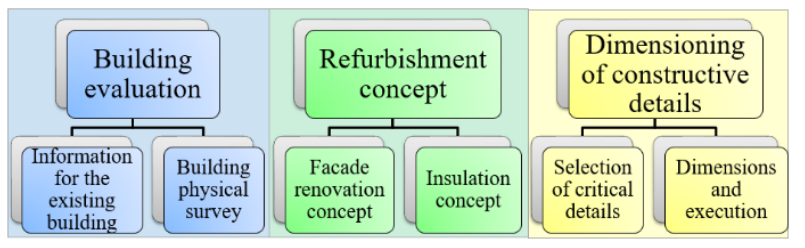

Fig. 1. Phases in the planning process of interior insulation measures

\section{Building evaluation}

The basis for a sustainable refurbishment concept is a comprehensive survey of the condition of the building. Only in this way it is possible to identify damage to the building structure, to assess the existing status with regard to thermal insulation, driving rain protection and sealing, and to identify special construction characteristics.

\footnotetext{
* Corresponding author: heike.sonntag@tu-dresden.de
} 


\subsection{Information on the existing building}

First, the existing planning documents and information on the building are viewed and taken into consideration. This provides information on the building structure and important connection details. Changes and conversions already carried out should be traceable. The more comprehensive the knowledge of the building's past history is, the better existing flaws and causes of damage can be explained from the conditions of its construction and the changes made. It proves to be very beneficial to have a first overview of the building before the on-site inspection.

\subsection{Building physical survey}

As an important basis for planning, a careful on-site inspection of the structural condition with recording of building damage and moisture loads is indispensable. Furthermore, structural conditions of the building are recorded, e.g. sandy surfaces, unevenness or cavities, which can be important for the planning. Special structural features such as steel girders or beams that penetrate the thermal envelope must be taken into account with regard to their position and condition.

A decisive boundary condition for the dimensioning of interior insulation systems is the driving rain impact on a facade. The driving rain load causes a considerable moisture load, which increases the risk of damage (high moisture content, ice formation) in the existing masonry when the interior insulation is applied, as the thermal behaviour of the existing wall is changed by the application of interior insulation. The drying potential of the existing construction is thus reduced.

During an initial on-site appointment, an orienting inspection of the building is carried out in order to gain an overview of its condition. On the basis of this visit, it is possible to assess which next steps are necessary for stock surveys and which survey methods will be used. Ideally, this inspection takes place after a rainfall event in order to be able to assess the capillary absorption capacity of the facade and to detect and document damage, e.g. in the splash water area and roof drainage, as well as its impacts. An example of this is shown in Figure 2, where it can be seen that high local moisture loads penetrate the facade construction due to nonfunctional temporary downpipes.

During a detailed inspection, usually at a further onsite appointment, the main focus is on the detection and investigation of the structural damage if the existing building is not functional. If necessary, measures for averting danger or (re)establishing the operability must be initiated promptly in order to avoid additional damage. In some cases, the cause of the detected structural damage can be easily removed, e.g. by replacing a defective roof drainage system or provisionally closing defects in the envelope structure. In the case depicted in Fig. 2 the down pipes had to be fixed right away to avoid the moisture accumulation in the wall.

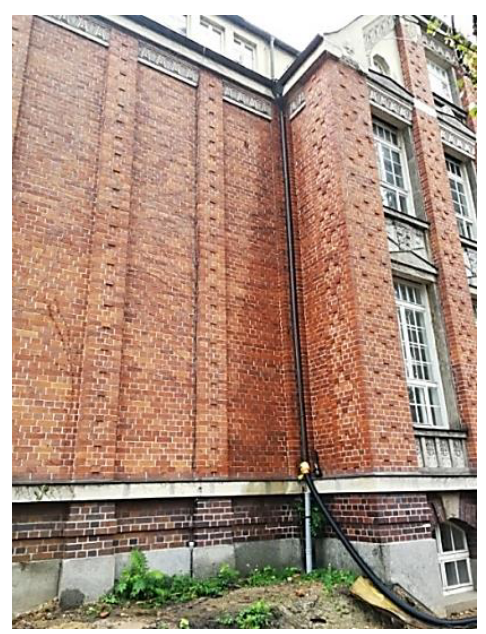

Fig. 2. Site inspection after a rain event; visible moisture load on the outer wall due to defective temporary downpipes

The first important findings for recording the condition of the building can be obtained with a sensory analysis without the use of extensive technical aids. Suggestions for this are listed in Table 1.

Table 1: Possibilities of sensory survey during the inspection of the object (examples)

\begin{tabular}{|l|l|}
\hline Sense & Information \\
\hline Seeing & $\begin{array}{l}\text { - Discoloration of surfaces as a result of } \\
\text { moisture penetration } \\
- \text { Mould growth, salt efflorescence } \\
- \text { Weathering, algae grow } \\
- \text { Characteristic of the structural elements }\end{array}$ \\
\hline Feeling & $\begin{array}{l}\text { - Sanding of surfaces (scratch test) } \\
- \text { Moisture exposure, e.g. on plaster } \\
- \text { Draught phenomena (lighter test) }\end{array}$ \\
\hline Smelling & $\begin{array}{l}\text { - Musty smell on/in wooden components } \\
- \text { Checking for plastic components in plaster } \\
\text { surfaces (lighter test) }\end{array}$ \\
\hline Hearing & $\begin{array}{l}\text { - Knocking on structural elements: detection } \\
\text { of cavities, material change }\end{array}$ \\
\hline
\end{tabular}

All sensory impressions are to be documented conscientiously.

As a result of the visual survey, a comprehensive and clear photo documentation is created. This includes systematic damage mapping in order to depict the structural condition as accurately as possible. Recognizable damage, such as moisture damage, salt contamination, rot, mould and algae, corrosion, etc., and constructive peculiarities are described in their position and form and entered into the plans (floor plans, views). At the same time, the mapping of the in-situ measurements (e.g. moisture content measurements and measurements on the capillary water absorption of the facade) is carried out, as correlations often arise here. The results of a damage mapping can be used to derive measures to eliminate the damage itself and causes of the damage. 


\subsubsection{Moisture measurements to determine the moisture status of wall constructions}

If a building is temporarily unheated and unused or if there is a maintenance backlog, there is often moisture damage to the building. In these cases and in buildings with non-functioning driving rain protection, it is necessary to check the moisture status of the wall structures before planning and implementing a renovation measure. There are various methods for measuring the moisture content with different requirements and accuracies. Basically, a distinction is made between indirect (non-destructive) and direct (destructive) measuring methods (see Fig. 3). In the case of the direct measuring methods, whose accuracy is potentially greater, material samples of different sizes must be taken.

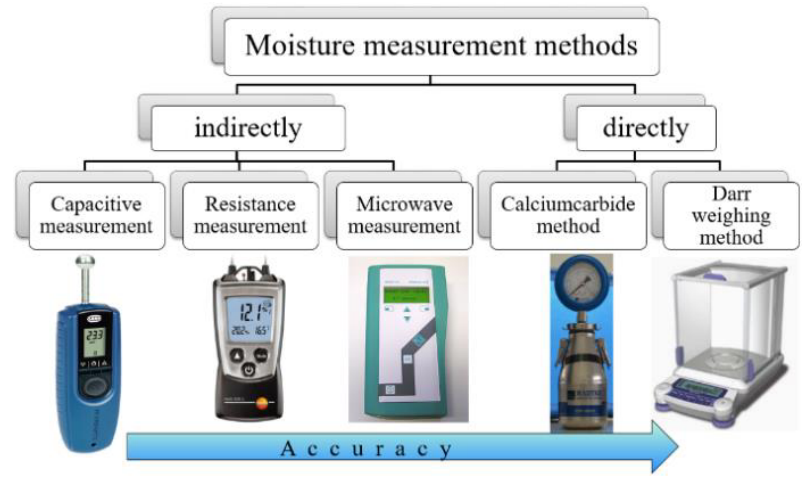

Fig. 3. Commonly used moisture measurement methods for the analysis of existing buildings.

Depending on the condition of the building, it is recommended to first carry out comparative measurements between dry and damp wall sections using a simple, near-surface indirect method and, in the event of abnormalities, to use more precise measurements such as microwave measurements or direct measurement methods. Depending on type and location of the moisture load, conclusions can be drawn as to its origin.

For example, moisture on the inner surface indicates condensation; moisture in the building component core indicates longer lasting moisture load, e.g. rising damp and non-functional sealing (see Fig. 4 for an illustration).

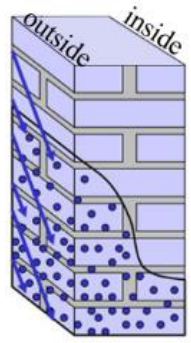

Rain load

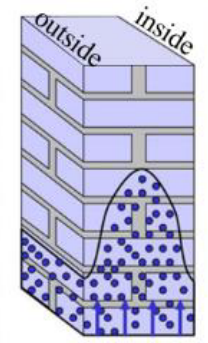

Rising moisture

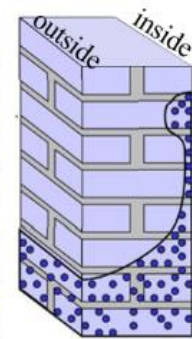

Hygroscopic moisture load

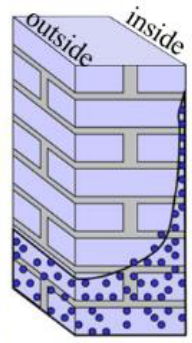

Condensation
Fig. 4. Schematic representation of moisture distribution in masonry [2]
Fig. 5 illustrates the result of a moisture distribution measurement in a wall. In this case the main problems are in the core of the wall, which indicates rising damp in the wall.

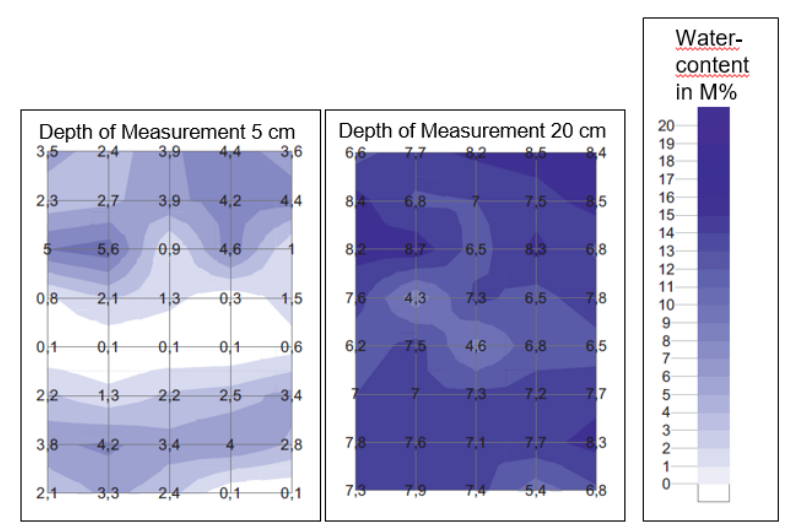

Fig. 5. Moisture distribution in a external wall in different depths of measurement with hints to rising damp

\subsubsection{Measurement of the capillary water absorption of the facade}

One of the most important criteria for the planning and design of interior insulation measures is the assessment of the driving rain load and driving rain protection of the individual facades of the building. Figure 6 lists various possibilities for measuring capillary water absorption.

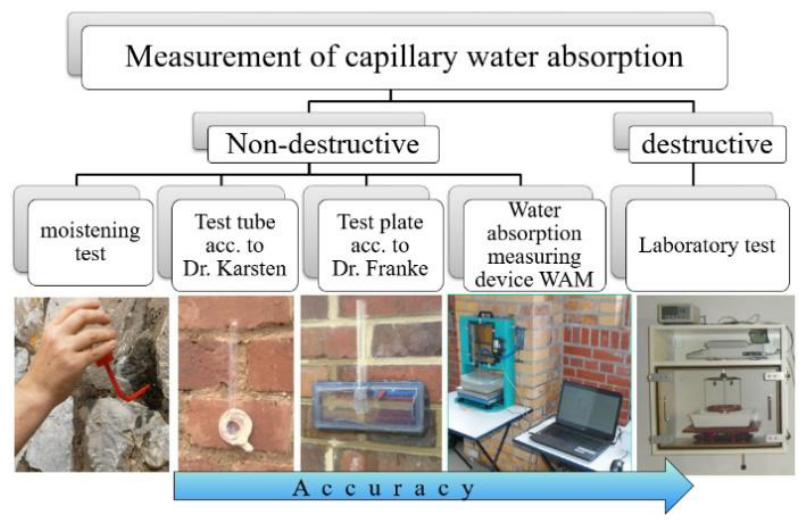

Fig. 6. Overview of measuring methods for determining the water absorption capacity of a building material

Depending on the required accuracy, either an orienting estimation (moistening test, test tube or test plate) or an exact measurement of the water absorption coefficient (e.g. with the water absorption device or absorption experiment in the laboratory) can be performed. It is important to ensure that a sufficient number of measurements are carried out, i.e. that several facade areas are covered in order to obtain representative results. In general, the smaller the test area on the facade, the more measurements are required.

If simple tests indicate that the driving rain protection is not sufficient for the existing bricks, a laboratory measurement is recommended. Material samples are required for this. There are different ways to gain bricks. One possibility is to take a drill core, another, to remove 
a whole brick, as shown in Fig. 7. The samples taken can then be used for further measurements. For example, the concentration of the active substance content for an adaptive hydrophobic impregnation can be determined if required. Fig. 8 shows an example of the effectiveness of such a measure on an existing brick. The capillary water absorption was first measured for the untreated brick. On this basis, it was determined which substance concentrations would be tested for the concrete material in order to be able to make a recommendation for the execution.

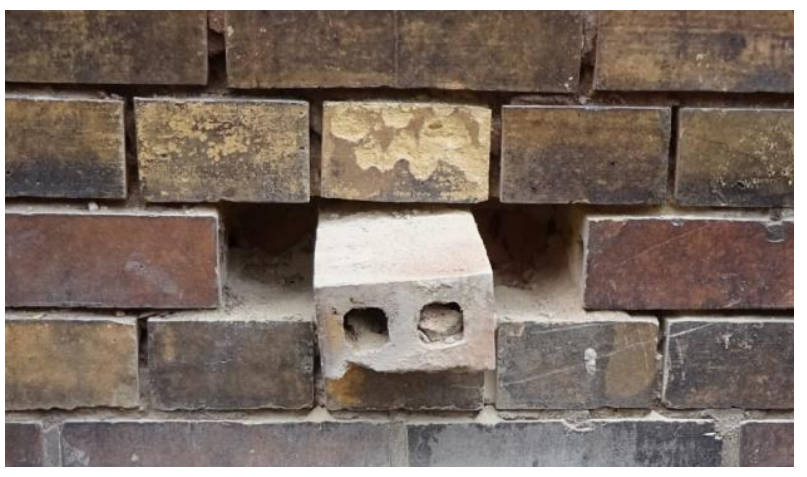

Fig. 7. Possibility of sampling by removing the joints and taking a whole brick. In this case it is easy to fill the area with a replacement brick.

Water uptake

Building 3, brick 2

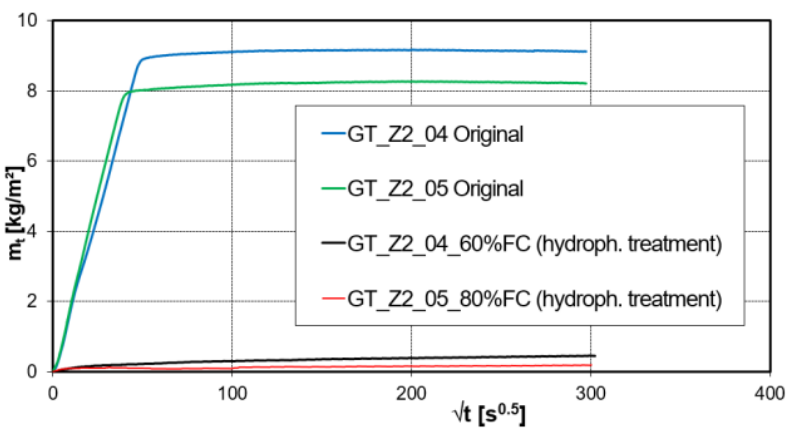

Fig. 8. Measurement of the capillary water absorption of the original brick (blue and green curve) and with adaptive hydrophobic impregnation with different concentrations of active ingredients (black and red curve)

\subsubsection{Thermographic investigations}

As a supplement to the inventory analysis, thermographic examinations of components and component connections can be carried out if there is a sufficient temperature gradient between the outside and inside. This allows to identify causes of heat loss. These include thermal bridges, air leaks, defects and cavities in the construction. Locally occurring moisture damage can also be easily detected with the help of thermography.

\subsubsection{Determination of material properties}

Depending on the requirements, the renovation goal and the scope of measures, it is necessary to have a more detailed knowledge of the physical properties of the existing structure as a requirement for the dimensioning of interior insulation systems.

Extensive databases are available (partly free of charge, e.g. www.altbaukonstruktionen.de or www.masea-ensan.de), from which specific values of historical materials and construction structures can be obtained. They can at least be used as orientation for frequently used constructions.

If the on-site measurements or the available plans and information are not sufficiently informative, further investigations, e.g. laboratory measurements on material samples taken from the wall cross-sections, may become necessary. The most important building physical values in this context are the vapour diffusion resistance and the water absorption coefficient of the outer surface layer (e.g. natural stone, clinker or existing outer plaster) as well as the thermal conductivity of the existing wall construction (e.g. brick-construction or construction of natural stone). The more complex laboratory measurements offer a significantly higher measurement accuracy than on-site tests. Especially for brick or natural stone facades, an exact assessment of the capillary water absorption is often necessary to classify the driving rain protection of the facade. This knowledge is also used to evaluate driving rain protection measures.

\subsubsection{Recommendations for action}

The results of the comprehensive survey are summarized in a building and moisture status report. This enables the calculation of necessary immediate and interim security measure, further investigations and procedures, time scheduling of individual trades as well as further planning and execution steps. This leads to more planning security and cost control for all participants involved in the development of the building-specific renovation concept.

The report contains a characterised list and map of any moisture damage found. Recommendations for dehumidification are given depending on the moisture load and horizons. In addition, advice is given on how to deal with existing salts. Necessary and recommended waterproofing measures are explained with detailed notes on the position and overlapping of its individual components.

\section{Refurbishment concept}

\subsection{Facade renovation concept}

The protective function of a facade decreases over the years due to weathering and other influences. Depending on the facade material and quality, appropriate maintenance cycles should be planned. Before a planned interior insulation measure, the condition of the facade must be examined in detail to ensure that the necessary driving rain protection of the facade is provided.

For plastered facades with an intact (or planned) exterior rendering, protection against driving rain is usually given or can be achieved by repairs in 
association with a water-repellent new coating. In this case no separate planning services are required.

The development of a facade renovation concept makes sense if the renovation effort cannot be easily estimated due to the existing complexity. This applies, for example, to natural stone facades or facades with visible bricks, where compliance with driving rain protection cannot be guaranteed, or to facades with obvious damage.

Together with the concept advice on the repair of joints and cracks and on the handling of salts are provided, as well as a suggestion for a gentle cleaning method suitable for the facade. Criteria and limit values for possibly necessary material exchange are named on the basis of previous investigations. In addition, necessary measures for the creation of driving rain protection are assessed. This can be, for example, the use of an adaptive hydrophobic impregnation for a brickfaced facade. Whether the selected hydrophobic agent is effective and suitable for the specific facade can be determined by laboratory tests.

\subsection{Insulation concept}

On the basis of the knowledge gained from inventory analysis, moisture analysis, driving rain exposure as well as material investigations, an insulation concept for the energetic refurbishment of the specific building can be created. First of all, the insulation goal, design and construction requirements, possible restrictions and the budget must be fixed together with the client. Then, possible insulation systems are determined and proven against the background of damage prevention, reduction of heating energy losses, requirements for the preservation of historical monuments and use-related particularities. Recognized damage and moisture loads must be eliminated before the implementation of the renovation measures. If this is only possible to a limited extent, the selection of the insulation system and the intended insulation thickness must be adapted accordingly.

Depending on the insulation standard and driving rain protection, the verification is carried out as a prooffree construction, with a simplified verification or as a complete verification with a hygrothermal simulation. In the latter case, a hygrothermal calculation of the actual state of the existing structure is first carried out with the given boundary parameters. This should allow the existing physical state of the construction to be reproduced. This calculation serves as reference calculation for the following verifications. In this context it is also possible to evaluate the drying potential of moisture-loaded constructions by means of hygrothermal simulations.

Only then is the planned construction with selected interior insulation systems verified. This allows the influence of the insulation measure on the construction to be demonstrated. Within the insulation concept, these calculations are usually carried out as one-dimensional calculations for the undisturbed wall cross-section. However, it may be useful to model constructions in more detail (e.g. as 2D model including joints as illustrated in Figure 9), to assist communication with the client.

The minimum thickness of the internal insulation results from the requirements of the minimum hygienic thermal protection. For most insulation materials, this is fulfilled with an insulation thickness of $3-5 \mathrm{~cm}$. It should be noted that with increasing insulation thickness the influence of thermal bridges, but also the risk of frost for the existing construction increases. Therefore, connection details must also be considered even more precisely with greater insulation thicknesses. In most of the projects of the authors, insulation thicknesses of 5-8 $\mathrm{cm}$ were used for capillary-active diffusion-open interior insulation, less frequently also $10 \mathrm{~cm}$.

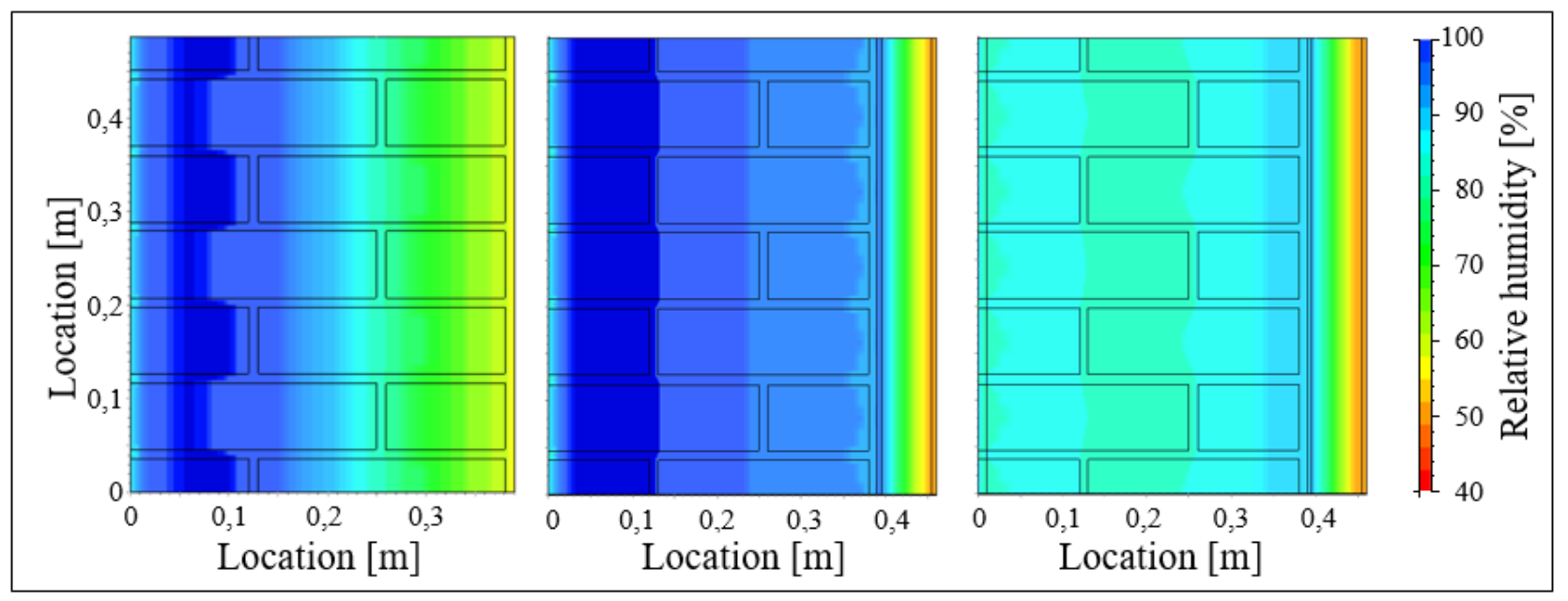

Fig. 9. Humidity field of a brick-faced outer wall construction; uninsulated construction (left) and with 5 cm capillary-active, diffusion-open inner insulation (middle), each without driving rain protection, and the insulated construction with application of an adaptive hydrophobic impregnation (right), snapshot of the hygrothermal simulation [4] on 24.02. of the 3rd calculation year 


\section{Dimensioning of connection details}

Good documentation in conjunction with the planning documents makes it possible to identify many critical points related to hygrothermal behaviour and damage risk. The professional recording and assessment of these thermal and moisture bridges is a focal point in the planning of interior insulation measures. For the execution on the construction site it has proven to be very useful to provide as good and detailed execution details as possible in order to be able to give clear instructions for action and thus to reduce the damage potential considerably.

\subsection{Selection of critical connection details}

After the general verification of the internally insulated construction, the examination of critical connection details takes place within the framework of further planning. This usually concerns the following thermal bridges (see also Fig. 10):

1 External corners of walls

2 Binding inner walls

3 Window lintel, reveal, parapet, also roller shutter

4 Connection jamb wall to roof construction

5 Verge and other roof connections

6 Binding ceiling tiles

7 Balcony connections

8 Pillar

9 Connection outer wall to basement ceiling

10 Interior walls on basement ceiling

11 Pedestal areas

12 Penetrations through the thermal envelope (steel girders, reinforced concrete floors and covers, ...)

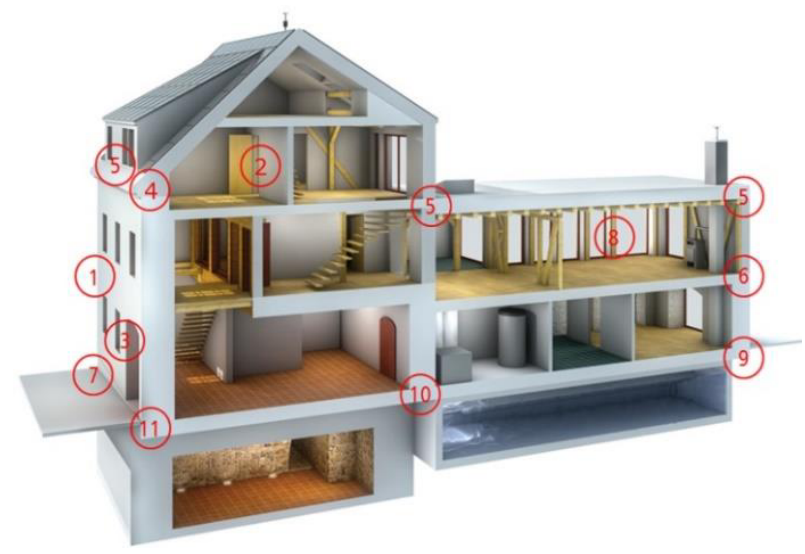

Fig. 10. Representation of common critical connection details in buildings with internal insulation [3]

\subsection{Dimensioning and execution}

In the planning phase before the actual detailed planning, the question usually arises as to how much space is required, e.g. for reveal and flank insulation. Based on many years of experience with capillary-active interior insulation, the following recommendations for the dimensioning of preliminary planning can be given. Within the framework of the implementation planning, an adjustment must be made for the concrete object according to the on-site conditions and the existing construction.

\subsubsection{Window reveal/ window lintel}

In reveal and lintel areas of existing buildings there is usually little space available for insulation. In many cases it is sufficient to use about half of the standard insulation thickness of the internal insulation for the reveal (with the same insulation properties). When using insulation with a lower thermal conductivity in this area, the insulation thickness of the reveal insulation can be reduced if necessary (see Fig. 11).

In this context, particular attention must be paid to the formation of the joint between the masonry and the frame. A continuous insulation level between this joint and the reveal insulation must be ensured. This transition is a typical weak point in a renovation.

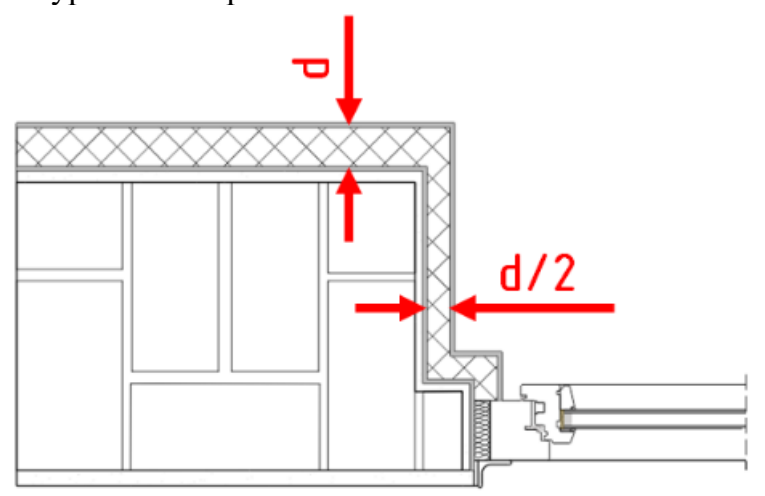

Fig. 11. Recommendation for the pre-dimensioning of an internally insulated window reveal

\subsubsection{Binding inner wall}

In order to reduce thermal bridges, it is advisable to optimise the corner areas on connecting solid interior walls. Whether it is necessary depends above all on the thickness of the outer and inner wall. The thinner the existing outer wall and the thicker the integrating inner wall, the greater the necessity of installing flank insulation in this area. It can be roughly assumed in the preliminary planning stage that flank insulation to ensure minimum thermal protection will be necessary if the inner wall is about half as thick or thicker than the outer wall (with the same wall materials)

In many cases it is then sufficient to use about half of the standard insulation thickness of the internal insulation for the flank insulation (with the same insulation properties). As an embedding length for the flank insulation, $30-50 \mathrm{~cm}$ are usually sufficient (see Fig.12). The flank insulation can be designed as insulation board or as insulation wedge. Another possibility is the use of so-called thermal angles. These consist of perforated aluminium sheeting with a thin rear insulation layer, so that the corner area can be designed unobtrusive without a protrusion. 


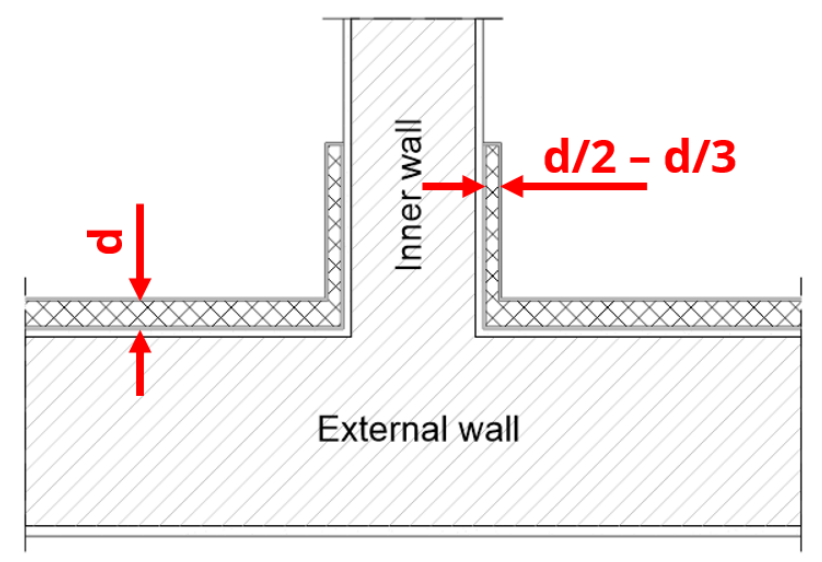

Fig. 12. Recommendation for the pre-dimensioning of an integrating inner wall

\subsubsection{Binding ceiling tiles}

Flank insulation is also usually required on solid ceilings (e.g. reinforced concrete ceilings). In many cases, it is sufficient to use about half the standard insulation thickness of the internal insulation for the flank insulation (with the same insulation properties). As an embedding length for the flank insulation $30-50 \mathrm{~cm}$ are usually sufficient (see Fig. 13). The installation of the flank insulation can be carried out in the same way as for the binding inner walls.

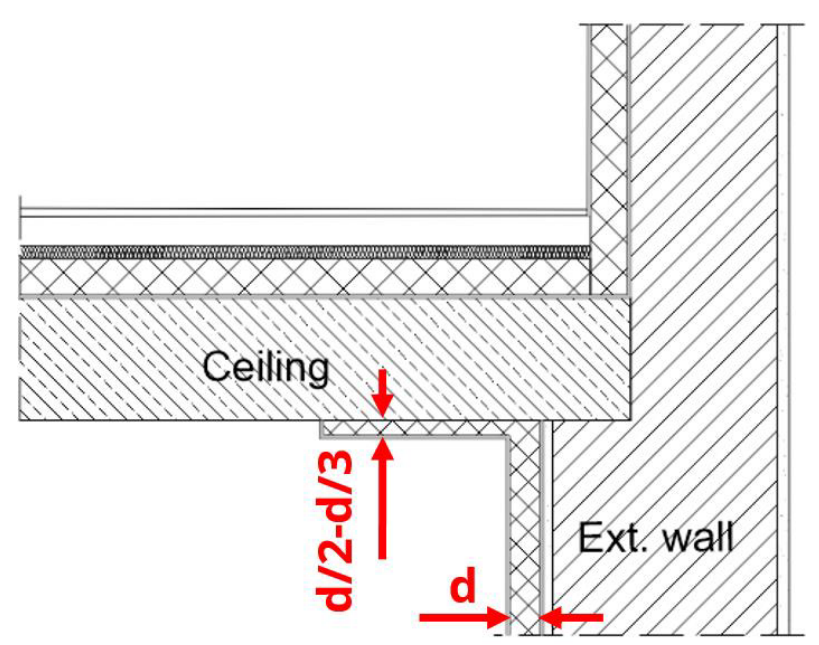

Fig. 13. Recommendation for the pre-dimensioning of an integrating solid floor ceiling

\section{Conclusion}

Sustainable renovations in connection with the application of interior insulation always require cautious step-by-step planning, with an important focus on the analysis of the existing situation. So the specific boundary conditions of the building can be taken into account in the most optimal way.With the projects carried out by the authors in recent years, this approach has become more and more concrete, so that with this experience a renovation guideline could be developed, with which recommendations for the necessary investigations and measurements can be summarized compactly. Thus a tool can be made available, with which a knowledge transfer from theory to practice can take place. The sensible use of hygrothermal simulation tools for the assessment and sustainable optimisation of critical situations in terms of building physics is an important aspect of this strategy. One goal for the coming period is the transfer of these findings into an online tool, so that the user can be guided interactively through the individual renovation phases in the future.

This focus is also being addressed in completed and ongoing research projects, e.g. RiBuild [5] and In2EuroBuild [6].

\section{References}

1. H. Sonntag, C. Conrad, R. Plagge, Sanierung des denkmalgeschützten Gebäudeensembles des ehemaligen US-Hauptquartiers in Berlin, 3. Innendämmkongress, Tagungsunterlage, TU Dresden, 2015, p.145 ff

2. T. Steiner, Bauphysikalische Prozesse vs. Schadensprozesse, Österreichisches Institut für Bauen und Ökologie $\mathrm{GmbH}$, https://slideplayer.org/slide/13942388/, Vom 10.01.2020

3. C. Conrad, J. Kost, Energy efficiency solutions for historic buildings, A Handbook, Birkhäuser Verlag $\mathrm{GmbH}$ (2014), p.296

4. DELPHIN 6.1, https://bauklimatikdresden.de/delphin/index.php

5. Robust Internal Thermal Insulation of Historic Buildings - RIBuild, Europäische Union (EU), Horizon 2020 (H2020), grant no 637268 (20152019)

6. Consistant European Guidelines for Internal Insulation of Building Stock and Heritage In2EuroBuild, BMWi (CORNET), IGF-Nr. 247 EBG (2019-2021) 